\title{
What Media Helps, What Media Hurts: A Mixed Methods Survey Study of Coping with COVID-19 Using the Media Repertoire Framework and the Appraisal Theory of Stress
}

\author{
Amber Pahayahay ${ }^{1}$, BSN, MPH; Najmeh Khalili-Mahani, ${ }^{2,3}$, MEng, PhD \\ ${ }^{1}$ School of Public Health and Services, University of Waterloo, Waterloo, ON, Canada \\ ${ }^{2}$ PERFORM Centre, Concordia University, Montreal, QC, Canada \\ ${ }^{3}$ McGill Centre for Integrative Neuroscience, Montreal Neurological Institute, McGill University, Montreal, QC, Canada
}

Corresponding Author:

Najmeh Khalili-Mahani, MEng, PhD

PERFORM Centre

Concordia University

PC 2.207 PERFORM Centre

7200 Rue Sherbrooke O

Montreal, QC, H4B 1R6

Canada

Phone: 15148482424 ext 5370

Email: najmeh.khalili-mahani@concordia.ca

\section{Abstract}

Background: Social and physical distancing in response to the coronavirus disease (COVID-19) pandemic has made screen-mediated information and communication technologies (media) indispensable. Whether an increase in screen use is a source of or a relief for stress remains to be seen.

Objective: In the immediate aftermath of the COVID-19 lockdowns, we investigated the relation between subjective stress and changes in the pattern of media use. Based on Lazarus's transactional model of appraisal and coping, and building on an earlier similar survey, we hypothesize that individual differences in the appraisal of media predict variations in approach or avoidance of media for coping with COVID-19 stress.

Methods: Between March 20 and April 20, 2020, a brief snowball survey entitled: "What media helps, what media hurts: coping with COVID19 through screens" was distributed via Concordia University's mailing lists and social media (PERFORM Centre, EngAGE Centre, and Media Health Lab). Using a media repertoire method, we asked questions about preferences, changes in use, and personal appraisal of media experiences (approach, avoid, and ignore) as a result of the COVID-19 pandemic and investigated interindividual differences in media use by factors such as subjective stress, age, gender, and self-reported mental health.

Results: More than $90 \%$ of the survey respondents were in Canada and the east coast of the United States. From 685 completed responses, 169 respondents were "very stressed" and 452 were "slightly worried" about the pandemic. COVID-19 stress led to increased use of Facebook $\left(\chi_{3}^{2}=11.76, P=.008\right)$, television $\left(\chi_{3}^{2}=12.40, P=.006\right)$, YouTube $\left(\chi_{3}^{2}=8.577, P=.04\right)$, and streaming services such as Netflix $\left(\chi_{3}^{2}=10.71, P=.01\right)$. Respondents who considered their mental health "not good" were twice as likely to prefer streaming services as a coping tool for self-isolation. Women and nonbinary respondents were twice as likely than men to pick social media for coping. Individuals younger than 35 years were 3 times more likely to pick computer games, and individuals older than 55 years were more likely to pick network television or print media. Gender affected the appraisal of media (less in men than others $)$ in terms of avoid $\left(F_{1,637}=5.84, P=.02\right)$ and approach scores $\left(F_{1,637}=14.31, P<.001\right)$. Subjective mental health affected the ignore score (less in those who said "good" than others; $F_{1,637}=13.88, P<.001$ ). The appraisal score and use increase explained variations in worrying about physical and mental health stress due to increased screen time. A qualitative analysis of open-ended questions revealed that media (especially social networks) were important for coping if they provided support and connection through the dissemination of factual and positive information while avoiding the overflow of sensational and false news. 
Conclusions: The relationship between appraisal of media's positive and negative facets vary with demographic differences in mental health resiliency. The media repertoire approach is an important tool in studies that focus on assessing the benefits and harms of screen overuse in different populations, especially in the context of the COVID-19 pandemic.

(J Med Internet Res 2020;22(8):e20186) doi: 10.2196/20186

\section{KEYWORDS}

Netflix; social network; stress; COVID-19; information and communication technologies; survey; media; coping; infodemic; infodemiology

\section{Introduction}

\section{Background}

The necessity of social and physical distancing in response to the coronavirus disease (COVID-19) pandemic has made screen-mediated information and communication technologies (media) even more indispensable than before, raising concerns about harms or benefits of screen dependency or screen stress due to overexposure. Previously, we have examined the relation between subjective and quantitative measures of screen addiction and stress, and showed that, despite the heterogeneity of the patterns of screen use and types of stressors, a robust correlation existed between higher emotional and perceived stress, and higher likelihood of screen addiction, especially linked to social networking and entertainment-related activities [1]. However, we could not answer the question whether screen addiction caused higher stress levels or if higher stress motivated an escape into screens for coping. The unprecedented occasion of this global stressor, the COVID-19 pandemic, allows us to address this question.

There is a growing concern about the potential adverse effects of excessive screen time on emotional and physical health. To name a few harms, there is stress caused by an abundance of catastrophic news [2]; increased sedentary behavior and obesity [3,4]; sleep disorders [5]; and addiction to social media [6], computer games [7], online gambling [8], etc. Nevertheless, the debate about the directional relationship between stress and compulsive screen use is nuanced. A 2014 review by Ryan et al [6] indicated that the risks of developing an addiction to social networks may be related to use and gratification factors linked to relationship maintenance, passing time, entertainment, and companionship. In a 2018 meta-analysis of 56 independent samples (comprising >27,800 individuals), Marino et al [9] showed that the problematic use of Facebook was associated with internal motives such as coping and information-seeking, and external motives such as socialization and conformity, albeit with important moderating effects related to age and geographic location. The two main reasons for problematic Facebook use were related to the motives of reducing negative moods and meeting one's needs to cope or pass time [9]. Brailovskaia et al [10] investigated the link between daily stress and depression in samples of problematic Facebook users from Germany $(\mathrm{N}=531)$ and the United States $(\mathrm{N}=909)$. Individuals with depressive symptoms reported higher daily stress and higher Facebook use. Although they acknowledged the short-term benefits of using Facebook to cope with depression, the authors warned that this positive effect could lead to long-term maladaptation due to addiction [10].
The double-edged nature of social media harms or benefits has long been considered in adolescents. Tsitsika et al [11] evaluated a cluster sample of more than 10,000 adolescents in grade 9 or 10 from 600 classrooms from 6 European countries and found that, in younger adolescents, the heavy use of social networking was associated with lower academic performance, higher internalizing of problems, and loss of physical activity; conversely, however, in older adolescents, the same social networking use was positively correlated with social competence. In a recent qualitative study of over 100 individuals with stressful experiences, Lee et al [12] experimentally manipulated the direction of conversations in an online-support context and showed that, whereas conversations that focused on reconstruing the stress experience from a broader perspective had a helpful impact, those focusing on recounting the personal experience were likely to add emotional stress for participants. A content analysis of over 8 million online conversations (in Korean) about the Middle East respiratory syndrome (MERS) outbreak in South Korea showed that, although expressions of negative affect (anxiety and fear) were prevalent in online social media and discussion boards, informative news content was more likely to bring out expressions of positive (calm and composed) MERS emotions [13].

Mediating screens are designed to be beneficial though. The role of online social networks in facilitating information- and support-seeking, especially for mental health support, is important in understanding their relation to stress and screen addiction. In 2014, Griffith and Szabo [14] found that the most addictive forms of internet activity among a sample of 111 college-aged respondents were social networking (84\%), email and chatting (69\%), and watching videos $(35 \%)$, and that each of those addictions satisfied a specific need of the user and helped them to improve the quality of their life. In a follow-up survey study of 1057 internet users aged 16-70 years, this team reported that the greatest source of internet dependency was information- and news-seeking, and that more than $86 \%$ of screen addicts believed that it improved their life quality [15]. In 2017, Utz and Breuer [16] reported the results of a 6-wave longitudinal study (over 3 years), with a final attrition of 1330 representative internet users in the Netherlands, and showed that in all waves the users of social networks reported higher levels of online social support than nonusers, especially for seeking advice. In a 2019 survey study of more than 1000 young Irish adults (aged 18-25 years), Petrorious et al [17] showed that more than $82 \%$ relied on online search and more than $57 \%$ on online medical support sites for seeking mental health care from reliable sources. 
In our previous cross-sectional snowball survey of 650 respondents (aged 18-80 years), we showed that more than $95 \%$ considered the most important need for media technologies to be for communication and information-seeking, which was independent from perceived psychosocial stress or emotional factors such as irritability, anxiety, sadness, lack of motivation, and anger [1]. In this current study conducted in the immediate aftermath of COVID-19 shut downs in North America, we asked a subset of questions from our previous survey to specifically investigate: would higher levels of subjective COVID-19 stress predict increased media use, would subjective stress due to COVID-19 increase social and entertainment media use more than other uses, to what extent would individual differences (demographics, health, and perceived COVID-19 stress) predict variations in respondents' appraisal of media as a beneficial coping strategy, and what factors would predict individual's concerns about the health risks of increased screen time?

\section{Theoretical Framework}

Stress, coping, and media are complex multifaceted constructs, and it is important to consider the working definitions that frame this work.

\section{Stress}

First, the term Stress is one of the most frequently used (or misused) terms in today's health discussions, but it is not understood or even felt similarly across different cultures [18]. There are various standard stress questionnaires (such as the perceived stress scale) that help provide a quantitative index of stress, and there are psychophysiological experiments that measure the embodied experience of stress. However, the aim of this study is not to quantify different dimensions of stress, but to assess the respondent's subjective experience of stress. For the purpose of this research, we rely on Mason's [19] definition of stress, which suggests that the experience of conditions of novelty, unpredictability, threat to self, and sense of control will reproducibly trigger a neurophysiological stress response [20]. COVID-19 is a stressor because the rapid global disruptions caused by COVID-19 lockdowns are novel and unprecedented to the lives of many in North America and Europe (where most of our data is collected from). COVID-19 has created an unpredictable condition. Several levels of unpredictable outcomes are prevalent: how and when will this end, and what will be the human or financial toll? COVID-19 is perceived as threatening to every aspect of life, financially, socially, and even physically (as the illness seems to be grave). The public health measures to control the spread of the virus, as well as the unknown nature of the virus' mechanisms of spread and immunity challenge every sense of control. Besides restrictions about work, social distancing, and travel, how this virus will mutate or end is outside our locus of control.

\section{Coping}

Second, similar to stress, the term coping is also imprecise [21]. As a psychophysiological response, stress is a complex phenomenon [22], and individual differences in appraisal and coping determine the behavioral approaches that alter an individual's experience of stress [23]. When we are casually talking about stress, we are often referring to a challenge that forces us to cope, and coping can be influenced by a myriad of personal, social, and environmental factors that vary with nature [24] and culture [25]. Coping is also a context dependent experience, and there are currently numerous survey studies that are trying to understand differences in coping and resilience [26].

Our study is only focusing on whether using media can help cope with COVID-19 stress, and whether patterns of media use vary with factors such as age, gender, and self-assessment of mental and physical health. After the lockdown, various behavioral and interpersonal resources that would generally be available for coping with stress (for example, exercise and fitness centers, parks and recreational areas, one-to-one or group therapy activities, social support networks, or even medical doctors) became unavailable. Screens are currently the only safe (from contagion) tool for coping with social isolation, interruption of work, learning and finding critical information, as well as distracting oneself from boredom and anxiety.

Therefore, we have narrowed down the question of coping to a set of factors from Marino et al's [9] findings of the internal and external motives for using social networks for coping through information-seeking, conforming, socializing, enhancing mood, and passing time.

\section{Media Appraisal}

Third, we address the complexity of the relationship between coping and stress by referring to Lazarus and Folkman's Theory of Stress Appraisal and Coping. Briefly, the Appraisal Theory postulates that when confronted with a stressor, individuals engage in a primary appraisal of its relevance, potential benefits, and potential dangers. Whether they find it beneficial or dangerous, they will then enter the second phase of appraisal to identify resources that they have or resources that they need to recruit to meet the challenges of the stressor (see the first supplemental figure in Multimedia Appendix 1). Depending on an individual's abilities, personality, or the particularity of the circumstances, the process of appraisal is mediated by cognitionor emotion-based behaviors that motivate and shape an individual's approach to, or avoidance of, different response strategies (eg, cognitive- or emotion-based). This process of appraisal is repeated recursively until an individual finds a solution (or fails) [23]. We have previously proposed a conceptual mixed methods framework for studying interactions between media (such as serious games) and stress [27]. We repeat this iterative process here by recursively asking questions about sources of actual, perceived, or anticipated stress while investigating individuals' differences in use and preferences.

\section{Media Repertoire Approach}

Similar to our previous study [1], we use a repertoire-oriented framework that emphasizes the interrelation between different available technologies and the factors that influence an individual's choice in the amount of different media or content use [28]. Research into media use often involves assessing the amount and the type of media used by the public or identifying the reasons for, and meanings of, using a specific media type within a specific context. The specific context of this study was "coping with COVID-19 disruptions," and we were interested 
in comparing the prevalence of different types of media-related activities in the coping process.

The media repertoire framework includes a mixed methods analysis of large-scale surveys of use together with more qualitative research into individual preferences to bridge between the patterns of different media type use and differences in the meaning and affordance of each media for a particular person (or subgroups of people) within social contexts [29].

We defined demographics, extent of perceived stress, and beliefs about one's mental health as predictors of variations in media use and media appraisal (in the context of serving as coping tools, as well as in relation to their potential risks to mental and physical health). Hence, we encourage readers to keep these working definitions in mind for the interpretation of our findings.

\section{Methods}

\section{Data Collection}

Within days of the announcement of the lockdown in the province of Quebec (March 13, 2020), we deployed a brief multifactorial 16-item questionnaire using the SurveyMonkey platform [30]. A brief advertisement was distributed via PERFORM's mailing list, as well as various social media (Twitter and Facebook) accounts.

Coping with COVID-19: What media helps, what media hurts?

Please join us in a quick anonymous survey to assess which kinds of media and information technologies matter most in these extraordinary times? Do

they stress us, or help us cope better?

The survey was available only in English, as we aimed to reach an international community that could communicate via a common language. Because it was important to deploy the survey in the early phase of the pandemic, we made the length of the survey short enough to not take more than 5 minutes to ensure high completion rate. (We attained $>95 \%$ completion.)

To compensate for the brevity of the survey, which prevented us from quantitative assessment of stress and coping, we included two open-answer boxes and asked respondents to offer more details about three specific questions: how the pandemic was disrupting their life, what other coping methods than those we listed would they use, and how they envisioned a strategy for media to become a useful tool for coping.

The sample size calculation was based on a margin of error and confidence level rather than prevalence or expected effect sizes. With a $5 \%$ margin of error and a confidence level of $95 \%$, a minimum sample size of 384 was estimated to be sufficient to reveal differences in an average response to each survey question. The survey was advertised through email lists, the PERFORM Centre website, Facebook, and Twitter, as well as through the social media of EngAGE Centre for studies in aging, and the Media-Health.ca website and social media. The distribution lists alone contained at least 10,000 people, thus, obtaining the necessary sample size could be achieved even with a conservative completion rate of $5-10 \%$.

\section{Dependent and Independent Variables}

Table 1 summarizes the dependent and independent variables and corresponding questions that were tested in this survey. 
Table 1. List of variables.

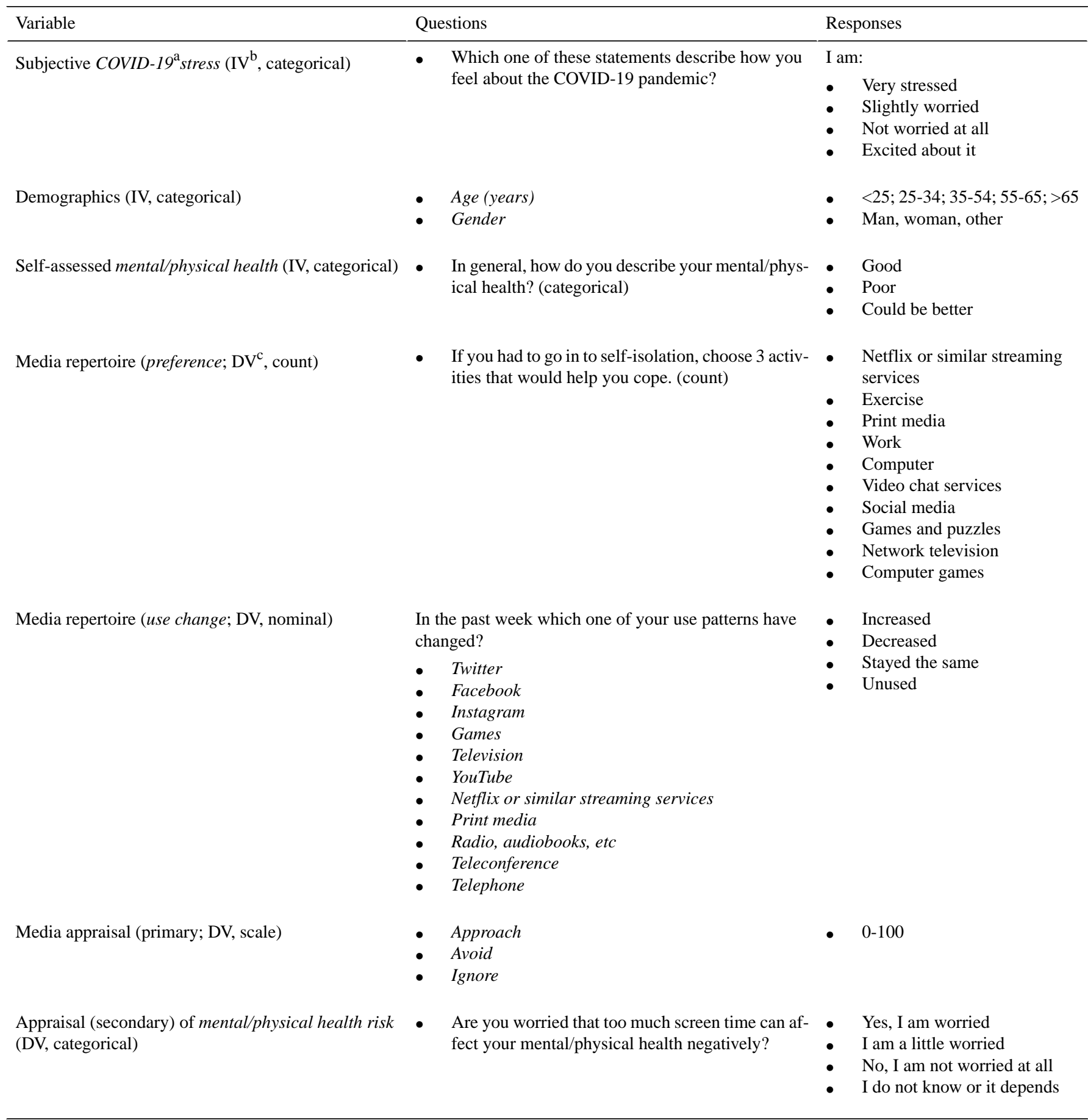

${ }^{\mathrm{a} C O V I D-19:}$ coronavirus disease.

${ }^{\mathrm{b}} \mathrm{IV}$ : independent variable.

${ }^{\mathrm{c}} \mathrm{DV}$ : dependent variable.

\section{Media Appraisal for Coping With the COVID-19 Pandemic}

Media appraisal was assessed based on an 8-item questionnaire, asking participants to state their opinions ("Definitely true," "Somewhat true," "Not really true," "Definitely false," or "I don't know") about the following statements: (1) I use social media to be connected while social distancing, (2) social media connects me to what is happening in the world, (3) COVID-19 news and social media posts overwhelm me, (4) social media spreads false information about COVID-19, (5) COVID-19 news gives me a sense of knowledge and control, (6) I play games or watch TV to distract myself from COVID-19, (7) there is too much media hype about COVID-19, and (8) I try to avoid the COVID-19 news as much as I can. The proportions of responses to each question are illustrated in Multimedia Appendix 2.

Using principle component analysis and varimax rotation, we reduced the appraisal questionnaire to 3 factors that cumulatively 
explained $57 \%$ of the variance in the sample. Factor 1 explained $21 \%$ of the variance (after rotation) loaded on items 1,2 , and 5. We refer to this factor as approach. The second factor explained $20 \%$ of the variance (after rotation) and loaded on items 3, 7, and 8. We refer to these factors as avoid. Finally, the third factor explained $16 \%$ of the variance loaded on items 4 and 6 . We refer to this factor as ignore. To compute scores for each factor, responses to each question were recoded as follows: definitely true was recoded to +2 , somewhat true was recoded to +1 , somewhat not true was recoded to -1 , and definitely false was recoded to -2 . We then computed the variables approach, avoid, and ignore by calculating the score of each factor by computing the normalized average of the items' scores in that factor. Interclass correlation coefficients of items in each factor were low (Cronbach $\alpha=.6$ ), which limits the reliability of these scores, but this scoring allows us to operationalize media appraisal.

\section{Statistical Analyses}

To compare associations between independent variables (age, gender, COVID-19 stress, and health status), we used contingency tables and chi-square tests of associations. To examine how different groups selected their coping resources, we computed the odds ratio of an activity being picked by each group category compared to the rest.

The Kruskal-Wallis and multivariate analysis of variance tests were used for group comparison of nominal dependent variables such as change in the media use and scale variable such as appraisal scores, respectively. In all cases, appropriate post hoc analyses were performed, and $95 \%$ confidence intervals were reported.

Prism8 (GraphPad Inc) and SPSS 24 (IBM Corp) were used for performing quantitative data analyses and presentation. The dropout rate (ie, respondents who accessed the survey but did not record their responses) was 49 out of 734. Because some of the survey questions were not mandatory, we present the case-wise sample size for each analysis. Details of statistical tests are presented together with results.

\section{Qualitative Analysis of the Open-Ended Questions}

We used Nvivo 12 for Mac (QSR Inc) and applied a data-driven approach to the coding of the open-ended questions by exploring the most frequently used words in the response boxes. We then explored the themes that related to disruptions caused by COVID-19 and coping strategies that mattered.

Out of the 689 respondents, 351 provided a response to the following question: "This outbreak has caused real problems, especially to those who do not have the ability to do their work from home. Can we envision ways in which the media (news, social networks, newsletters, etc) can be used to alleviate their burden?"

Nearly $11 \%$ (38/351) of those responses were "I don't know," "not sure," or "maybe" without any explanation. A little over $7 \%(26 / 351)$ responded with "No" or "Not really" without any explanation. About 5\% (20/351) responded "Yes" without any explanation.

Using a word frequency analysis on 267 spell-checked and corrected entries (automatically removing transitional verbs, prepositions, pronouns, conjunctions, articles, quantifiers, and adverbs) revealed that the words work (217 counts), home (145 counts), people (96 counts), social (84 counts), media (67 counts), time (66 counts), help (62 counts), school (53 counts), news (52 counts), activities (49 counts), information (48 counts), job (47 counts), online (43 counts), friends (38 counts), cancellation (38 counts), and family (35 counts) were the most frequent ones.

These words were extracted using Nvivo 12's word-query function. Statements that included each word were studied one by one to code for the following themes: the impact and disruption caused by the pandemic, what mattered to individuals in terms of coping with the pandemic, and what kind of help the media could provide. We then performed a node matrix query on each coded concept to create a network representing the co-occurrence of nodes (ie, the number of times that any two words were co-occuring in one statement). Finally, we used an open source software Gephi (version 0.9.2 for Mac, an open source and free software for visualization and exploration of any network types) [31] to identify the emerging concepts that were more important in the open-question responses. The network was partitioned by its modularity (a measure of how a network compartmentalizes into subnetworks), and the nodes were ranked by their eigenvector centrality (EC; a measure of node importance in the network). These results were then used to create a conceptual model for addressing the main question of the study: what media helps and what media hurts?

\section{Results}

\section{Sample Distribution in Age, Gender, Health, and COVID-19 Stress Groups}

Figure 1 shows the geographical location of the sample. The majority of responders were from Canada $(n=515)$. Descriptive statistics are presented in Table 2. COVID-19 had disrupted the normal life of more than $85 \%$ of respondents. Nearly two-thirds of the sample were women, and one-third were between the ages of 35 and 54 years. Less than one-third of the sample considered their mental or physical health to not be good. 
Figure 1. Geographic location of respondents.

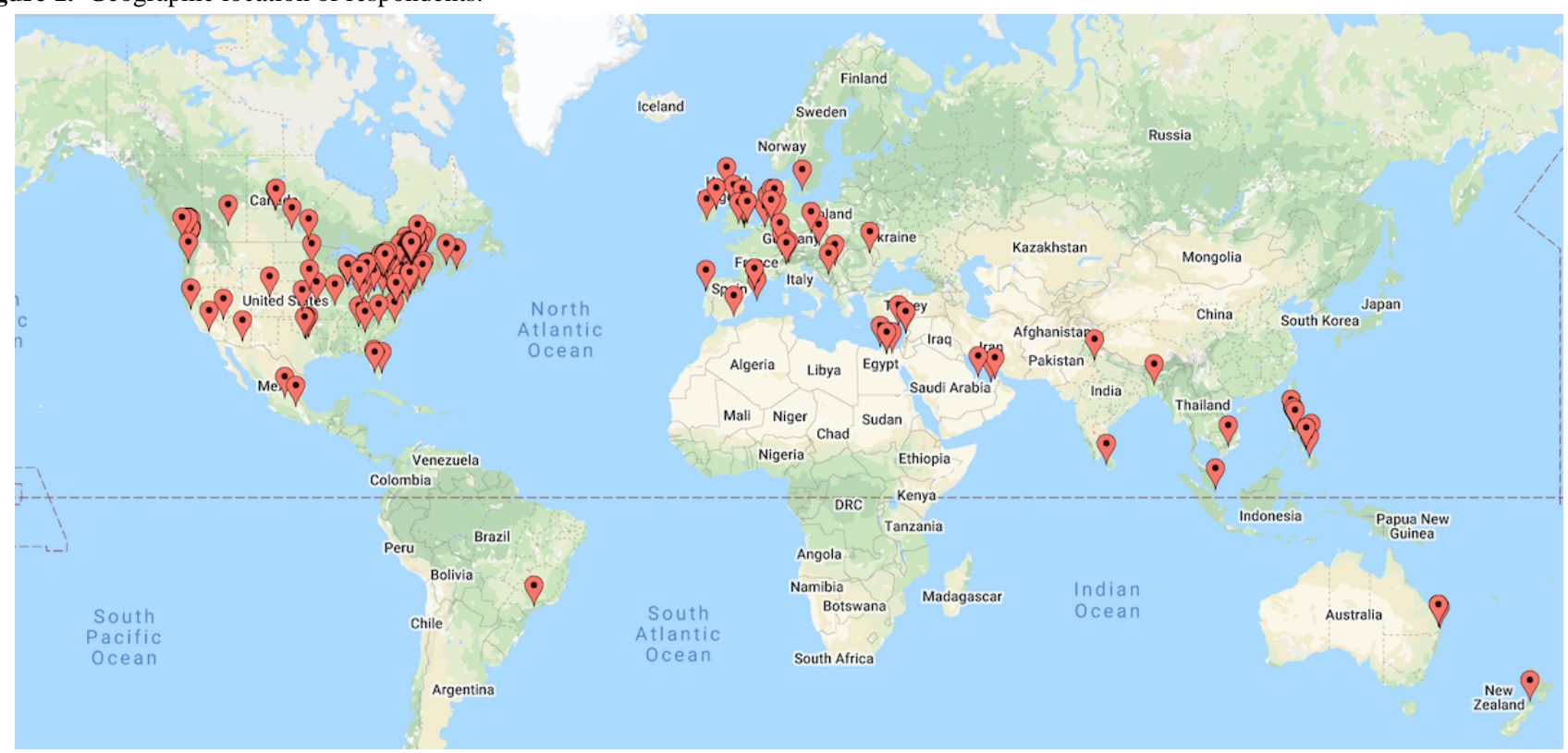


Table 2. Descriptive statistics.

Has COVID-19 ${ }^{\mathrm{a}}$ interrupted your normal life?

Yes

No

$57(7.8)$

Missing

$49(6.7)$

Which one of these statements describe how you feel about the COVID-19 pandemic?

$\begin{array}{ll}\text { Very stressed } & 169(23) \\ \text { Slightly worried } & 452(61.6) \\ \text { Not worried } & 50(1.4) \\ \text { Excited about it } & 10(1.4) \\ \text { Missing } & 53(7.2)\end{array}$

Are you in quarantine or self-isolation?

Yes

$354(48.2)$

No

$329(44.8)$

Missing

$51(6.9)$

What is your age category?

Younger than 25 years

84 (11.4)

25-34 years

165 (22.5)

35-54 years

259 (35.5)

55-65 years

88 (12)

Older than 65 years

89 (12)

Missing

$49(6.7)$

What is your gender?

Male
Female
Nonbinary
I prefer to not answer this question
Missing

179 (24.4)

$494(67.3)$

$4(0.5)$

8 (1.1)

$49(6.7)$

Generally, how would you describe your mental health?

Good

496 (67.6)

Poor

28 (3.8)

Could be better

$156(21.3)$

Missing

54 (7.4)

Generally, how would you describe your physical health?
Good
$512(69.8)$
Poor
$9(1.2)$
Could be better
$166(21.3)$
Missing

${ }^{\mathrm{a} C O V I D-19:}$ coronavirus disease. 
Group Differences in Perception of COVID-19-Related Stress

Chi-square test of contingency showed no association between categories of COVID-19 stress perception and age $\left(\chi_{12}^{2}=5.04\right.$, $P=.96)$, but associations with gender $\left(\chi_{6}^{2}=15.05, P=.03\right)$, self-assessed mental health $\left(\chi_{6}^{2}=30.93, \quad P<.001\right)$, and self-assessed physical health $\left(\chi_{6}^{2}=20.83, P=.002\right)$ were significant. As can be seen in Figure 2, men were half as likely to be "very stressed" by COVID-19 (odds ratio $0.48,95 \%$ CI $0.31-0.75)$, and those with good mental health were also less likely to be "very stressed" (odds ratio $0.415,95 \%$ CI 0.29-0.60). We found a significant association between self-assessed mental health and age $\left(\chi_{8}^{2}=41.2, P<.001\right.$; a higher proportion of young respondents considered their mental health as poor or could be better) but there was a nonsignificant association with gender $\left(\chi_{4}^{2}=8.8, P=.07\right)$.

Figure 2. Perceptions of COVID-19 stress across age, gender, and self-assessed health groups. COVID-19: coronavirus disease.

COVID-19 Stress by Age

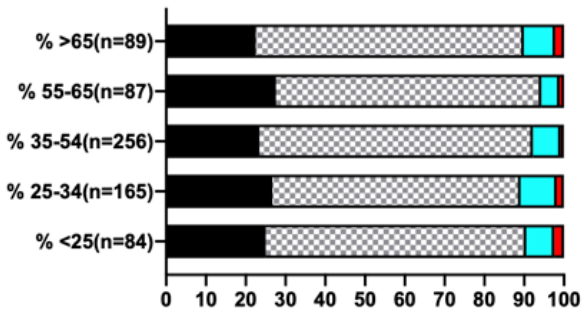

COVID-19 Stress by Mental Health

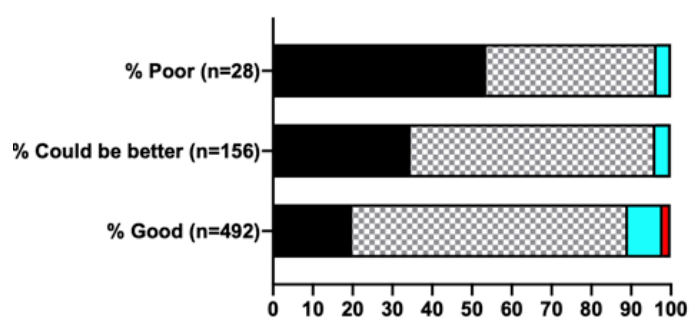

\section{Group Differences in Media-Type Preferences for Coping With Self-Isolation}

The ranked counts of activities that individuals picked as the three most important for helping them cope with self-isolation and quarantine are presented in Multimedia Appendix 1. The most frequently selected option was Netflix or similar streaming services $(402 / 685, \sim 60 \%)$. Netflix is not the only online streaming technology but the first of this genre; for simplicity, we use the name of this brand to refer to any streaming services of this kind (eg, Amazon Prime, Hulu, Home Box Office, Crave, Disney, GEM)

Interestingly, exercise was the second (358/685) and print media $(264 / 685)$ the third most important activities.

However, when splitting the sample across age and gender, the within-group proportions of responses revealed different patterns (Figure 3).

In terms of age, individuals younger than 35 years were two times more likely than the rest of the sample to pick Netflix or similar streaming services (odds ratio 2.04, 95\% CI 1.46-2.85) and 2.3 times more likely to pick computer games (odds ratio $2.28,95 \%$ CI $1.43-3.63$ ) for coping in a quarantined condition. By contrast, individuals older than 55 years were twice more
COVID-19 Stress by Gender

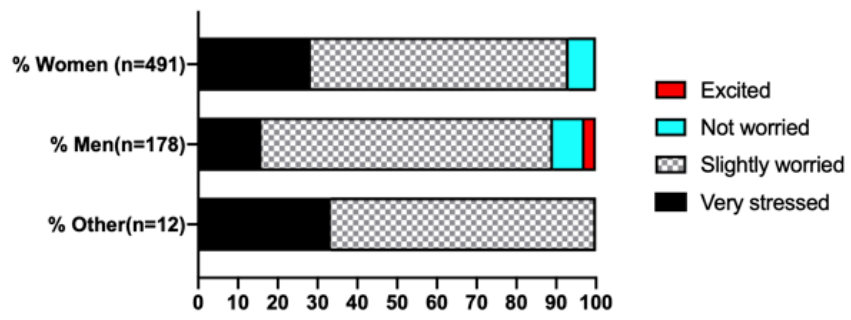

COVID-19 Stress by Physical Health

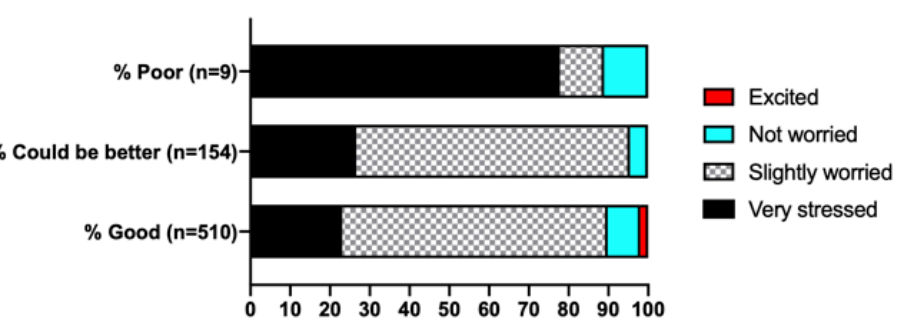

likely to pick print media (odds ratio $2.02,95 \%$ CI 1.43-2.87) and more than three times likely to pick network television (odds ratio 3.39 , 95\% CI 2.16-5.32) compared to those who were younger. To have a work computer was most important for those aged 35-54 years (odds ratio 1.82, 95\% CI 1.32-2.5). The odds of using social media, teleconferencing, exercise, and solo games or puzzles were not significantly different between groups.

In terms of gender, the few ( $\mathrm{n}=12)$ who did not specify a binary gender showed visibly different odds in terms of preferences, but in the absence of a large enough sample, we will not discuss the statistical significance of these findings. However, comparing men $(n=179)$ and women $(n=494)$ showed that men were twice more likely than women to pick work computer (odds ratio 1.45, 95\% CI 1.02-2.06), three times more likely to pick computer games (odds ratio 3.3, 95\% CI 2.05-5.27), and 1.8 times less likely to pick social media (odds ratio $0.55,95 \%$ CI 0.368-0.833) for coping with self-isolation in the case of quarantine.

In terms of mental health, those who indicated their mental health was good were 1.5 times more likely to pick work (odds ratio $1.46,95 \%$ CI 1.02-2.09) and more than twice less likely to pick Netflix or similar streaming services (odds ratio 0.428 , $95 \%$ CI 0.30-0.62). Other differences were not significant. It is 
worth mentioning that those who indicated their physical health was good were more likely to pick exercise (odds ratio $2.4,95 \%$ CI 1.67-3.44), but other differences were not significant.
With the exception of one response ("reading good fiction books"), no other respondents suggested alternative coping activities.

Figure 3. Group differences in preference for activities to cope with self-isolation or quarantine.

\section{Age by Activity Preference}

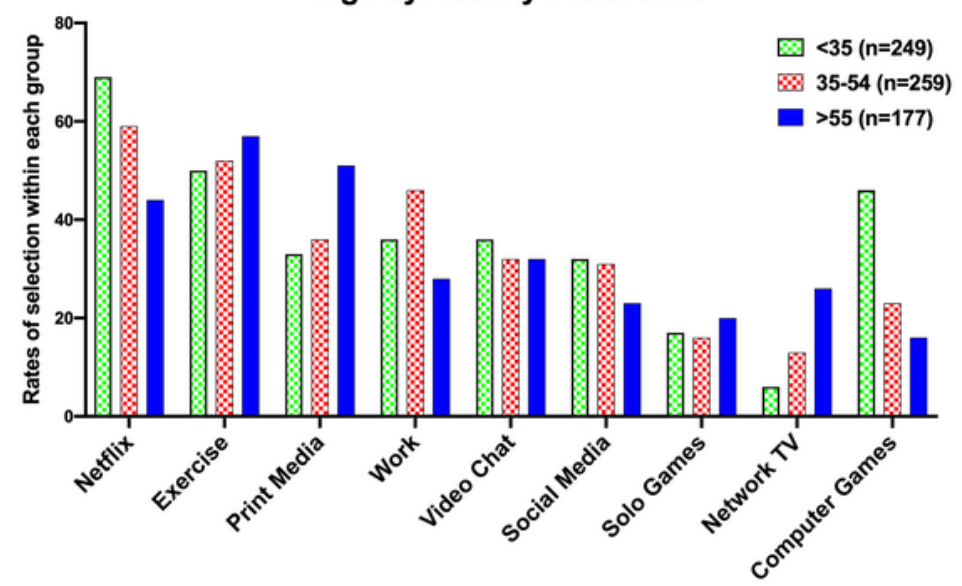

Gender by Activity Preference
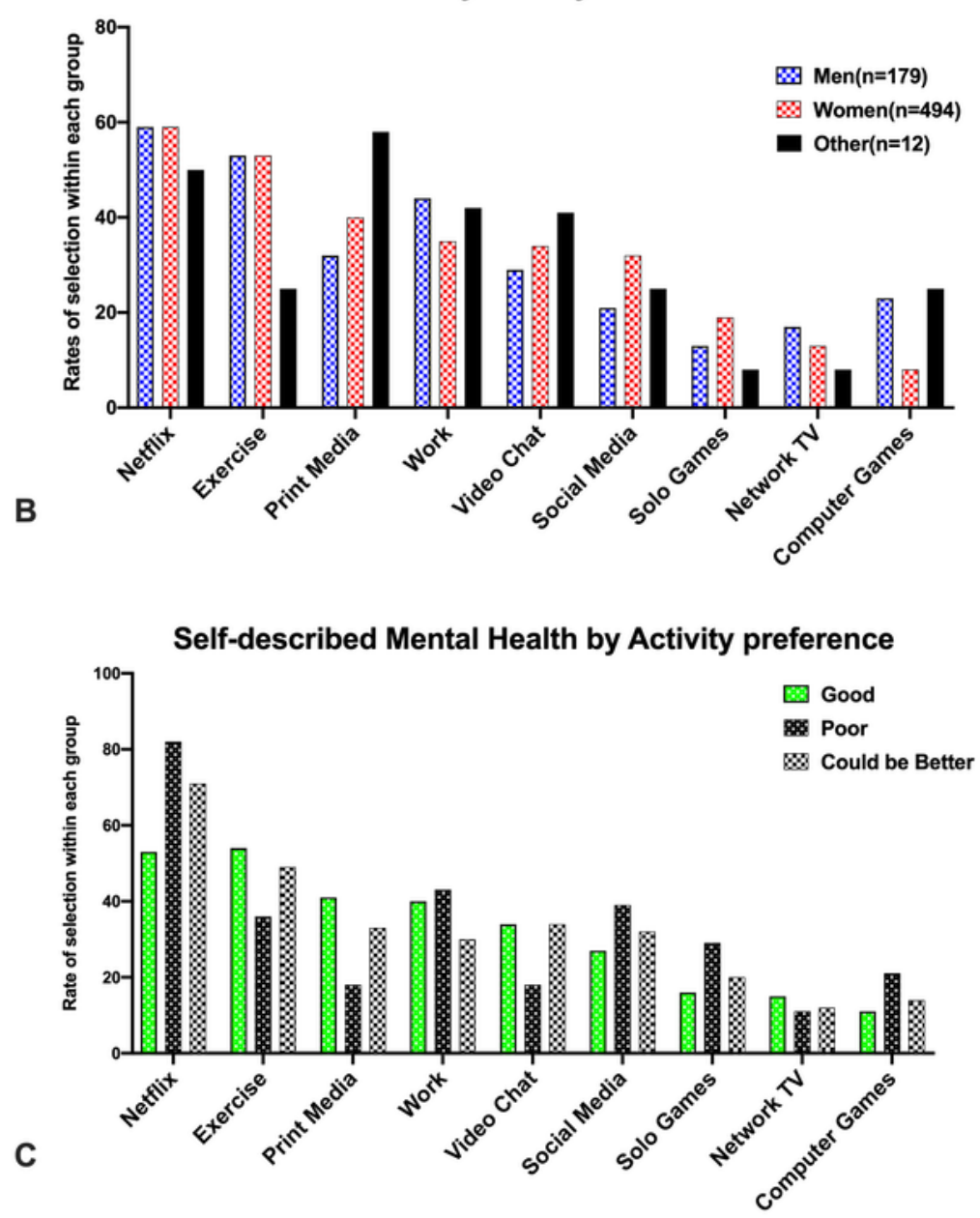

Table 3 provides the response frequency to how media use has changed as a result of the COVID-19 pandemic. The highest frequency of increased use was in video chat, followed by telephone and Netflix or similar streaming services. The highest frequency of unchanged use was with print media and YouTube.
The highest frequency of unused media was Twitter (also with the lowest rate of increase), followed by games (although its use increased), Instagram (although its use also increased), and audio media. 
Table 3. Frequency of response to changes in media use as a result of the coronavirus disease pandemic.

\begin{tabular}{lllll}
\hline Media repertoire use & Unused, $\mathrm{n}(\%)$ & Decreased, $\mathrm{n}(\%)$ & Unchanged, $\mathrm{n}(\%)$ & Increased, $\mathrm{n}(\%)$ \\
\hline Video chat $(\mathrm{n}=329)$ & $44(13.4)$ & $2(0.3)$ & $25(7.6)$ & $258(78.4)$ \\
Telephone $(\mathrm{n}=328)$ & $36(11)$ & $6(1.8)$ & $124(37.8)$ & $162(49.4)$ \\
Netflix or similar $(\mathrm{n}=667)$ & $118(17.7)$ & $14(2.1)$ & $262(39.3)$ & $273(40.9)$ \\
Facebook $(\mathrm{n}=664)$ & $131(19.7)$ & $26(3.9)$ & $246(37)$ & $261(39.3)$ \\
Television $(\mathrm{n}=664)$ & $160(24)$ & $26(3.9)$ & $256(38.6)$ & $222(33.4)$ \\
YouTube $(\mathrm{n}=664)$ & $149(22.4)$ & $14(2.1)$ & $294(44.3)$ & $207(31.2)$ \\
Print media $(\mathrm{n}=334)$ & $61(18.3)$ & $17(5.1)$ & $162(48.5)$ & $94(28.1)$ \\
Games $(\mathrm{n}=644)$ & $312(48)$ & $9(1.4)$ & $159(24.4)$ & $164(25.5)$ \\
Instagram $(\mathrm{n}=636)$ & $278(43.7)$ & $27(4.2)$ & $172(27)$ & $159(25)$ \\
Audio media $(\mathrm{n}=321)$ & $137(42)$ & $21(6.5)$ & $97(30.2)$ & $66(20.6)$ \\
Twitter $(\mathrm{n}=627)$ & $405(64)$ & $9(1.4)$ & $116(18.5)$ & $97(14.2)$ \\
\hline
\end{tabular}

The Kruskal-Wallis test (with Dunn's correction for multiple comparison of post hoc pairwise comparisons) was used for these analyses.

In terms of age, differences in the mean ranks of use were statistically significant for the following:

- $\quad$ Twitter $\left(\chi_{4}^{2}=19.38, P=.001\right)$ : predominantly higher in those aged 25-34 years, with significant differences in those older than 65 years (mean rank difference $=62.8$, adjusted $P=.02$ ) and younger than 25 years (mean rank difference $=62.3$, adjusted $P=.04)$

- Instagram $\left(\chi_{4}^{2}=56.14, P<.001\right)$ : predominantly decreasing with age (adjusted $P$ values<.004)

- $\operatorname{Games}\left(\chi_{4}^{2}=18.0, P=.001\right)$ : predominantly and significantly higher in the two age groups younger than 35 years. It is notable, however, that the differences between game use of those older than 65 years were not significantly different from those younger than 25 years or between 25 and 34 years (adjusted $P$ values $>.89$ ), and that the mean ranks of the game use in those older than 65 years were higher than those between the ages of 55 and 65 years.

- Netflix or similar streaming services $\left(\chi_{4}^{2}=21.1, P<.001\right)$ : generally decreasing with age but statistically lower in those older than 65 years and younger than 35 years (adjusted $P$ values <.004)

- Videoconferencing $\left(\chi_{4}^{2}=26.74, P<.001\right)$ : with statistically significant differences between the age group that was older than 65 years and those younger than 25 years (adjusted $P<.001$ ), those aged 25-34 years (adjusted $P=.02$ ), and those aged $35-54$ years (adjusted $P<.001$ )

In terms of gender, differences in the mean ranks of use were statistically significant for Facebook $\left(\chi_{2}^{2}=7.66, P=.02\right)$ - higher in women (adjusted $P=.02)$ - and Instagram $\left(\chi_{2}^{2}=19.07\right.$, $P<.001$ ) - higher in women (adjusted $P<.001)$. However, other use differences were not statistically significant ( $P$ values $>.2)$.

In terms of mental health, differences in the mean ranks of use were statistically significant for Instagram $\left(\chi_{2}^{2}=6.91, P=.03\right)$,
YouTube $\left(\chi_{2}^{2}=12.14, P=.002\right)$, and Netflix $\left(\chi_{2}^{2}=11.04, P=.004\right)$, and higher in those who stated their mental health "could be better" versus those who considered their mental health "good" with mean rank differences of Instagram $=41.6$ (adjusted $P=.01$ ), YouTube $=51.6$ (adjusted $P=.005$ ), and Netflix $=47.14$ (adjusted $P=.01)$.

\section{Link Between Subjective COVID-19 Stress and Change in Media Use}

Group differences in subjective COVID-19 stress ("slightly worried," "very stressed," "not worried," and "excited by it") and media use change (unused $=0$, decreased $=-1$, unchanged $=1$, increased=2) were significant for Facebook $\left(\chi_{3}^{2}=11.76, P=.008\right)$, television $\left(\chi_{3}^{2}=12.40, P=.006\right)$, YouTube $\left(\chi_{3}^{2}=8.577, P=.04\right)$, and Netflix $\left(\chi_{3}^{2}=10.71, P=.01\right)$ but not significant for any other activity $\left(\chi_{3}^{2}<7, P\right.$ values $\left.>.1\right)$.

The post hoc Dunn's pairwise comparison (with Bonferroni correction) indicated that the mean rank of Facebook use for those who were "Very stressed" (95\% CI 1.01-1.4) was significantly higher than those who were "Slightly worried" (95\% CI 0.91-1.16), with a mean rank difference of 48.37 (adjusted $P=.02)$, or "Not worried" (95\% CI 0.28-1.5), with a mean rank difference of 81.55 (adjusted $P=.03$ ).

The mean rank of television use for those who were "very stressed" (95\% CI 0.85-1.23) was significantly higher than the "not worried" group (95\% CI 0.25-1.08), with a mean rank difference of 99.47 (adjusted $P=.005$ ).

The mean rank of Netflix use for the "Very stressed" (95\% CI $1.02-1.44)$ was significantly higher than "Slightly worried" (95\% CI 1.15-1.36), with a mean rank difference of 73.81 (adjusted $P=.04$ ), or "not worried" (95\% CI 0.11-1.23), with a mean rank difference of 90.0 (adjusted $P=.01$ ).

Post hoc comparisons of YouTube did not yield significant results. These observations support our previous hypothesis that increased use of social media and passive entertainment is used as a coping strategy against stress. 


\section{Group Differences in Media Appraisal for Coping With COVID-19}

So far, we have shown significant demographic and health-related differences in media preference and changes in media use as coping strategies. To what extent are these differences explained by differences in appraisal?

We used a multivariate general linear model with an appraisal variable (approach, avoid, and ignore) as dependent variables and tested a full factorial model with age, gender, and mental health as independent variables, with Bonferroni correction for multiple post hoc comparisons. For simplicity of interpretations, nonbinary respondents were excluded, as their number was $<12$; mental health self-assessments "poor" and "could be better" were coded into "not good."

The multivariate Pillai's trace test (chosen because of its robustness to violations of model assumptions) revealed significant contribution to the model from gender by age $\left(F_{12,1911}=1.86, P=.04\right.$; Figure 4 ; mainly affecting ignore,
$\left.F_{4,637}=2.70, P=.03\right)$, from gender $\left(F_{3,635}=8.23, P<.001\right.$; affecting both avoid, $F_{1,637}=5.84, P=.02$, and approach, $F_{1,637}=14.31$, $P<.001$; Figure 4$)$, and from mental health $\left(F_{3,635}=5.13, P=.002\right.$; affecting ignore scores only, $\left.F_{1,637}=13.88, P<.001\right)$.

Post hoc comparisons (adjusted for Bonferroni correction) showed that, compared to men, women had significantly higher scores of both approach (95\% CI 9.44-31.405) - meaning that they found information, connection, and control in social media-and avoid (95\% CI 2.74-26.45) — meaning that they were more overwhelmed by COVID-19 news, found the media hype too high, and tried to avoid the news as much as possible.

Figure 5 illustrates that differences in mental health were associated with significant differences in avoid (95\% CI 1.7-17.97) and ignore (95\% CI 11.25-36.33), meaning that they watched television or played games to distract themselves from the news and considered media a source of false information. Differences in physical health were only associated with ignore.

Figure 4. Age- and gender-related differences in appraisal (mean, standard error of the mean).
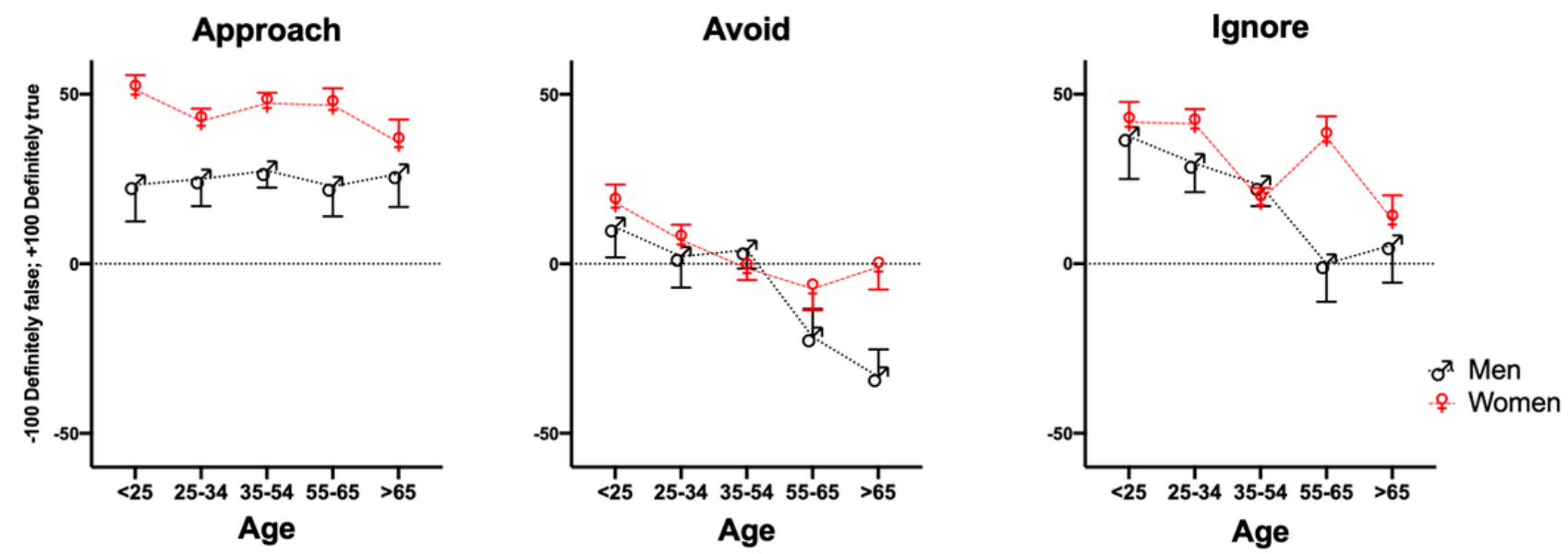

Figure 5. Physical- and mental health-related differences in appraisal (mean, standard error of the mean). Pairwise comparison of each variable independently shows significant differences related to self-assessed physical and mental health. We also found a significant likelihood that physical and mental health were related. $\left({ }^{*} P<.05 ; * * P<.005\right.$. $)$.

Self-assessed Mental Health

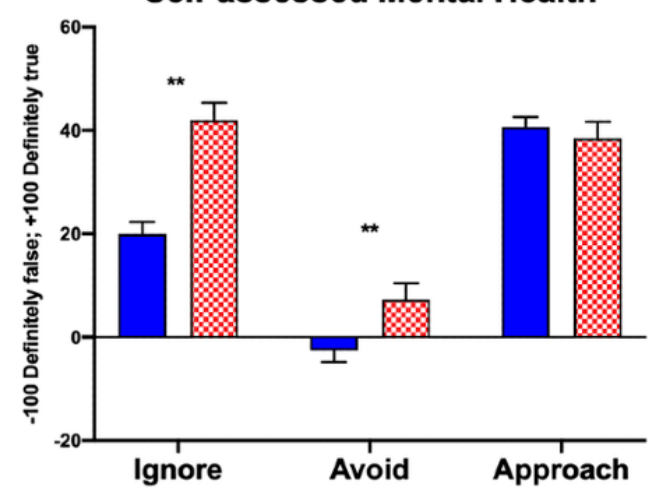

Good
Not good

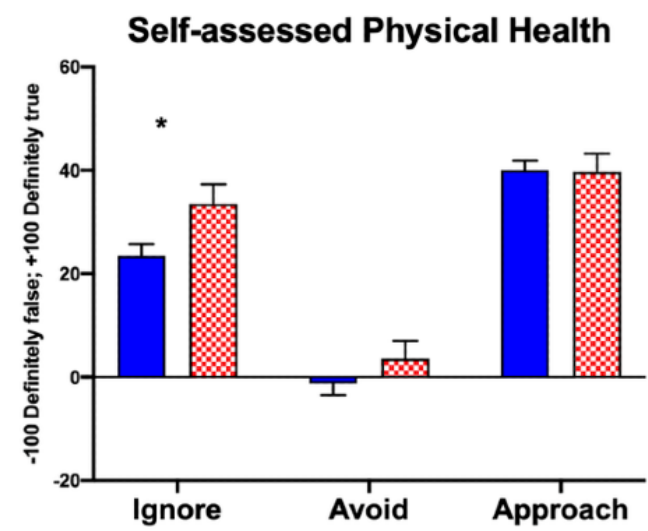

Good
图 Not good 


\section{Relationship Between Appraisal, Use, and Worry About Mental and Physical Health Risks of Increased Screen Time}

In the third week of the sampling, when the possibility of overusing screens for work and entertainment had become higher than before, we added two questions and asked whether users were concerned about increased time on screens becoming physical or psychological stressors (Figure 6).

Figure 6. Relation between media appraisal, media use, and perceived risk of mental and physical health deterioration as a result of increased media use. * shows media types whose usage was significantly different between groups $(P<.05)$.

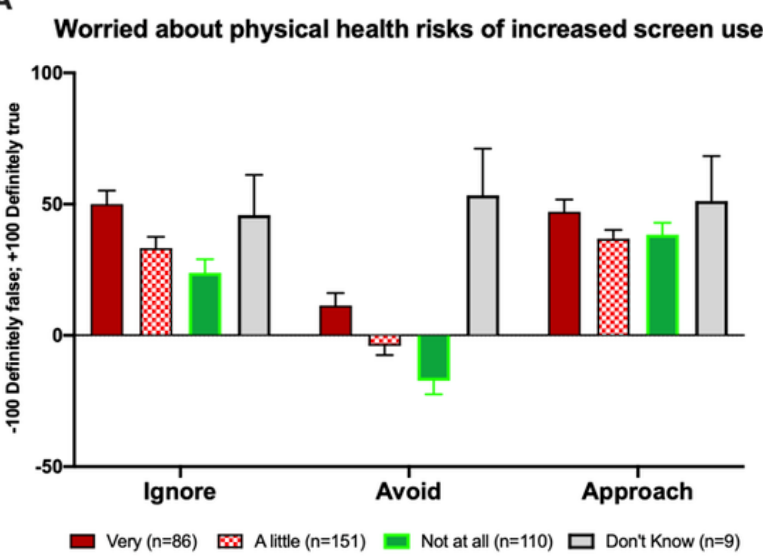

B

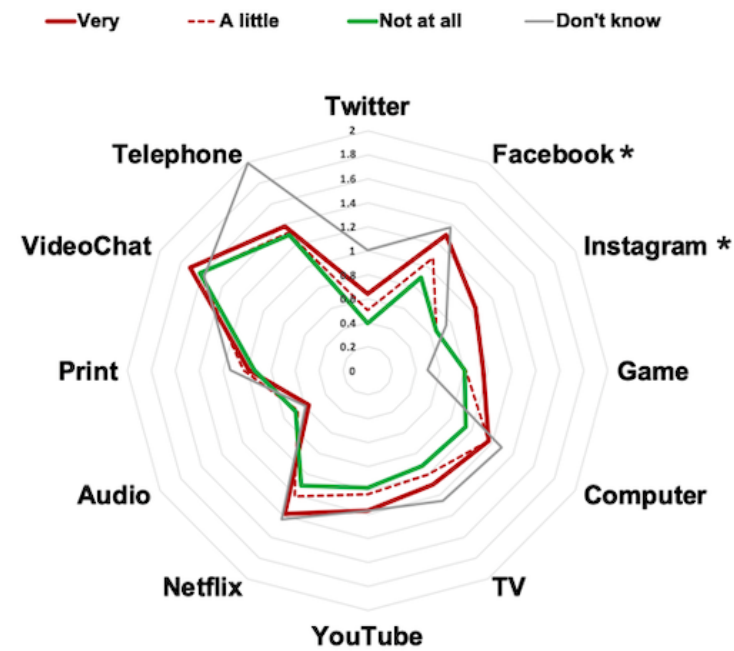

In response to "Are you worried that too much screen-time can affect your physical health negatively," 86 responded "Yes," 151 responded "a little," 110 responded "Not at all," and 9 responded "I don't know."

In response to "Are you worried that too much screen-time can affect your mental health negatively," 41 responded "Yes," 152 responded "a little," 107 responded "Not worried at all," 21 responded "I don't know," and 33 responded "It depends."

A total 14 respondents further commented that they were concerned for anyone who might develop addiction or detrimental lifestyle habits (especially children). These were recoded into "Yes." There were 10 other respondents that mentioned the necessity of balance; using screens for exercising, making art, seeking information, and online learning was positive, but using them for all-day television watching was bad; using in moderation was good, but addiction was bad. We recoded these responses to "a little." There were 8 respondents
Worried about mental health risks of increased screen use

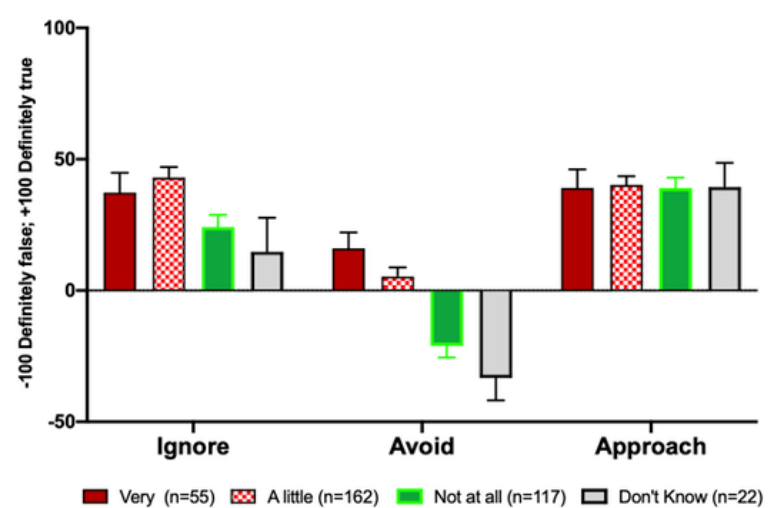

D

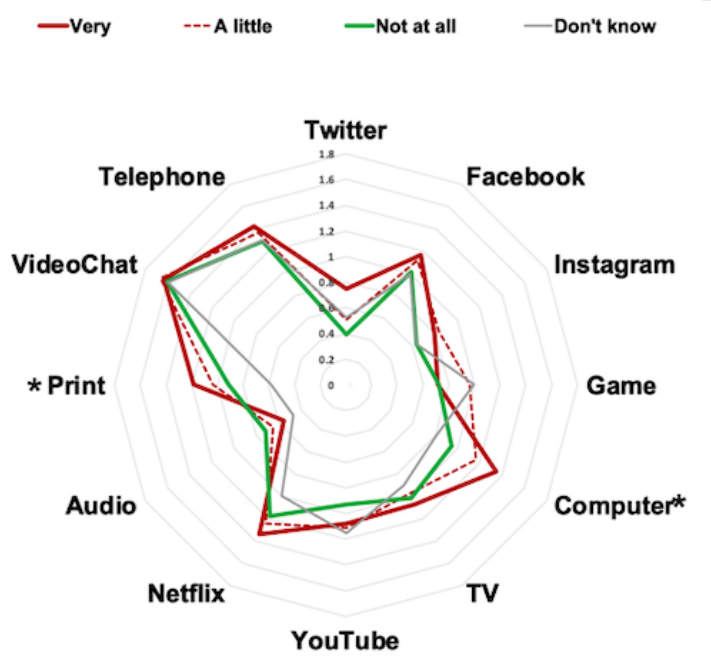

that indicated that they had control over the time they spent on screens and that, during COVID-19, the screens provided them with an opportunity to "educate themselves and their kids," "exercise," and "distract from boredom." These responses were recoded to "not worried at all." There was 1 respondent that indicated that they did not understand the question (this response was coded to "I don't know").

Responses to the questions of concern were congruent in $53.9 \%$ (192/356), meaning that respondents expressed the same degree of concern about physical and mental health risks.

A multivariate analysis of variance with appraisal variables as dependent and mental or physical health risks of screen time as predictive factors showed significant association between ignore and mental health risk $\left(F_{3,350}=13.9, P=.009\right)$ and physical health risk $\left(F_{3,350}=4.27, P=.006\right)$. Avoid was also associated with worry about mental health risks $\left(F_{3,350}=14.5, P<.001\right)$ and physical health risks $\left(F_{3,350}=5.55, P=.001\right)$ - in both cases, those 
who were very worried ignored and avoided the media more than others.

Figure 6 illustrates that concern for mental and physical health risks were associated with significant differences in some media's use. The Kruskal-Wallis test showed that those who were worried about mental health risks had significantly different use patterns mainly related to increased use of work computers $\left(\chi_{3}^{2}=7.95, P=.047\right)$, print media $\left(\chi_{3}^{2}=10.08, P=.02\right)$, and there was a nonsignificant use pattern for Twitter $\left(\chi_{3}^{2}=7.55\right.$, $P=.06)$. In contrast, those who were worried about physical health risks had increased use of Facebook $\left(\chi_{3}^{2}=10.88, P=.01\right)$ and Instagram $\left(\chi_{3}^{2}=9.18, P=.03\right)$ but a nonsignificant trend for increase in Netflix $\left(\chi_{3}^{2}=6.99, P=.07\right)$.

\section{Qualitative Analyses of the Open-Ended Questions}

Our qualitative analyses were data driven in that we simply counted the number of words that were most frequently mentioned in response to the open-ended questions, namely, "How has COVID19 disrupted your normal life?" and "Can we envision ways in which the media (News, Social networks, newsletters, etc.) can be used to alleviate the burden?" (see the word cloud in Multimedia Appendix 3). Responses that focused on the impact of COVID-19 included frequent references to anxiety, job (work and home), and lifestyle (activity, cancellations, and time). Responses that discussed affordances of different media types included frequent mentions of the words information (often together with facts), how-to tips and learning opportunities, news (which could be hurtful if overly negative), and support (social media and specific support networks). In terms of what was important for users, we found frequent mention of words like access and affordability, government, health, connection, positivity, and truth.

Looking at the linkage between these nodes revealed three network communities $(\mathrm{Q}=0.301)$, which are represented in different colors (Figure 7). The letter size of each network node represents the importance of the node in terms of EC. The three communities were associated with three important nodes. Positivity was the most important one because it was linked to other important nodes such as information, support, connection, and how-to. The second most important node was work and was mostly represented by nodes that related to the impact of COVID-19. The third most important network was information and was mostly represented by nodes that referenced importance of facts, news, truth, social media, and "hurt," which referred to comments about the detrimental impact of false news, sensationalized and politicized messaging, and stressful hype and catastrophizing. Examples of respondents' statements about positivity, information, and work are provided in Multimedia Appendix 4.

Figure 7. Results of qualitative network analysis. Colors represent network communities. The size of the letter is proportionate to eigenvector centrality (a measure of the hubness of each node). The thickness of edges reflects the weight of each edge.

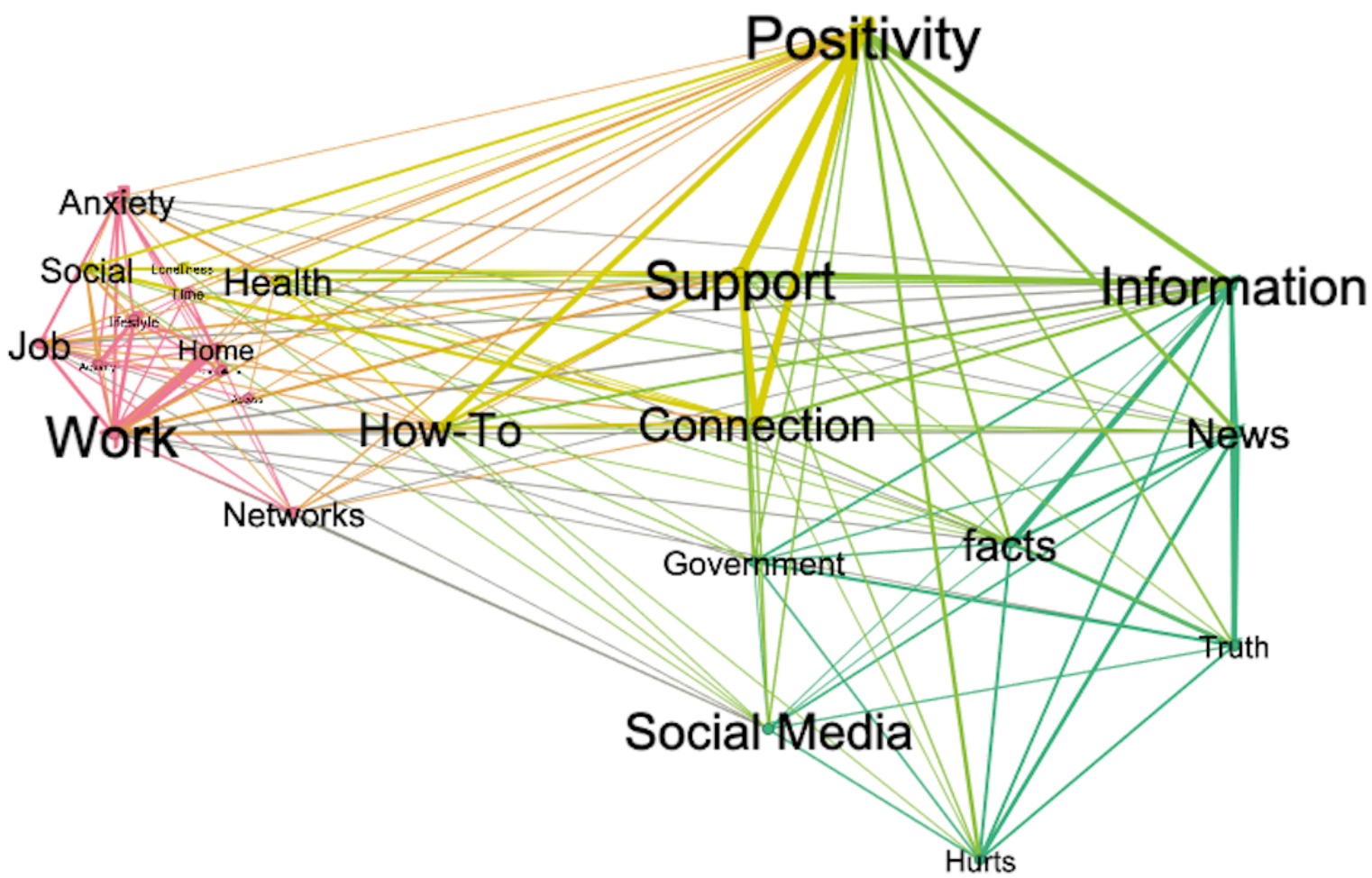




\section{Discussion}

In a follow-up to our previous work studying the relation between screen use and stress [1], we conducted a brief cross-sectional survey and asked a subset of questions based on the previous study to investigate whether higher levels of subjective stress predicted an increase in use of information, social, and entertainment media as means of coping with COVID-19 disruptions. Additionally, we asked questions to assess whether respondents worried that their increased dependency on screen-based communications was perceived as a risk to their mental and physical health.

\section{What Media Helps, What Media Hurts?}

One of the aims of this survey is to address the question of what screen-mediated interventions are needed to respond to the stress caused by the COVID-19 pandemic. Our position is that, in designing and promoting any digital health interventions, we must first ask whether the digitized intervention risks becoming a stressor in and of itself, and then mitigate those risks in design $[27,32]$.

Despite being a short survey, the mixed methods approach allowed us to explore our question from several angles: do the subjective intensity of feeling stressed by COVID-19 or the self-assessed state of mental and physical health explain variations in media use, and do we find similar results if we look at the question of media use from different perspectives, like choosing activities for quarantine, reporting on changes in use pattern, or appraisal of why to approach, avoid, or ignore media?

Indeed, we found converging results that all point to a close association between feeling stressed and reaching out to media for coping.

\section{Passive Viewing of Self-Curated Information or Entertainment Content Helps}

The first important finding is that media with passive (but selectable) viewing content were important for coping with COVID-19 stress. Increased uses of Facebook, Netflix, and television were significantly associated with the degree that individuals found the COVID-19 pandemic stressful-those who reported being "Very stressed" had higher use of these specific media. This supports our hypothesis that there is a causal relationship between subjective stress and higher dependency on social and entertaining media as coping strategies. Could it be that watching negative news was causing the added stress? Although we cannot reject this hypothesis, our results indicate that individuals who had higher levels of stress avoided and ignored such media more (Figures 5 and 6). In other words, the appraisal of media in relation to individual's needs motivated their approach to passive viewing but led to active avoidance and filtering of the negative content out of one's life.

This is consistent with a common finding in media studies that choice and self-determination can affect the evaluation of the situation and perceived satisfaction with media [6,14,33-35]. Studying the binge-watchers' motivations and affective states,
Castro et al [36] showed that relaxation, boredom relief, and escapism were the top reasons why individuals were attracted to streaming services and that watching certain content such as comedies would have a quantifiable effect on positive and negative affective state.

It is plausible to suggest that active choice-making, even when using passive media (streaming services, YouTube, Instagram), was the reason why these types were more important to those who reported that their mental health was not "Good." In general, Netflix or similar streaming services were the most frequently selected item for coping with social isolation (followed by exercise, print media, and work), but those whose mental health was not "Good" were twice as likely to pick Netflix or similar streaming services but twice less likely to pick work-perhaps suggesting a need for distraction from reality or killing time. In addition, use of other self-selectable viewing services such as YouTube and Instagram also increased in those with mental health dissatisfaction (mainly the young).

\section{Social Media Helps Women More}

The role of social media, as a coping tool was ambivalent. Four out of five respondents indicated that they used social media to be connected while social distancing and remaining connected to what is happening in the world, but many of them also thought that social media news was overwhelming to them and spreading false information.

Interestingly, social media was generally ranked less important than Netflix, exercise, and print media, although it was frequently discussed in the open-ended question (see word cloud in Multimedia Appendix 3). Several studies have pointed to a link between compulsive use of social media and mental health $[1,9,10,37]$. Although we found that preferences for social media were gender dependent, differences were not related to age or self-assessments of mental health. Women were more likely than men to pick social media to cope with isolation but less likely to pick work or computer games (but they were not different in other categories). Women also significantly increased their use of Facebook and Instagram after the COVID-19 lockdown, although they did not significantly differ from men in use of other media.

Ryan et al [6] have shown that dependency on social media is linked to gratification factors such as relationship maintenance, passing time, entertainment, and companionship. This explains women's preference for social media given that women of all ages had higher approach scores compared to men (Figure 3). Recall that approach relates to agreeing with the statement that social media provided an opportunity to stay connected while in isolation, to be informed, and to have knowledge and a sense of control. Interestingly, women, especially the older ones, and those with mental health complaints (Figure 4) also had slightly higher scores of avoid, which referred to finding too much hype, being overwhelmed, and trying to avoid the news about COVID-19.

\section{Unless Positive, News and Social Media Would Be Hurting}

Taking a data-driven network analysis approach, positivity emerged as the most central theme, connecting between different 
nodes related to the media's helpfulness in coping with COVID-19 stress. Refences to positivity had common nodes with support, information, and news (factual and nonsensational), as well as with opportunities for learning how to do new things or gain control by communicating with the government through social media. Positivity was also connected with the second most important node, work, which was central to the subnetwork that related to anxiety caused by COVID-19 and various practical interruptions such as losing jobs, working or not being able to work at home, and changing lifestyle and activities. Work was also strongly connected to support, information, and networking, which enables one to earn a living at home. As expected, information was central to the third subnetwork, with strong connections to facts and truth (which connected information to positivity), as well as to support (via social networks, how-to instructions, and connections.) An important connection between positivity was to the node hurts, which means that, although informing, connecting, educating, distracting, and encouraging were positive aspects of media, spreading false, fearful, and anxiety-increasing messages (due to politicization, sensationalization, or catastrophizing) were hurtful.

These observations confirm the findings of Hoog and Verboon [38], who used a momentary ecological assessment method for 63 participants who reported their affective state during 10 days of following the news and showed that exposure to bad news is a psychological stressor, albeit depending on personality factor. Marin et al [39] have also shown that exposure to negative news made women more susceptible to being physiologically responsive (in terms of cortisol release) to later experimental challenges (Trier stress test). Data in this survey suggest that self-awareness on the stressful nature of media adjusts how individuals adapt. Here, we showed that respondents who did not consider their mental health as "Good" or who worried that increased screen time would be a mental health risk had significantly higher avoid and ignore scores (Figures 5 and 6). It should also be mentioned that engagement with our open questions was higher in those who considered their mental health as good (see Multimedia Appendix 5). Thus, we note that this survey may not have reached those who find the current situation most stressful and who will be the target for media-based stress-reduction interventions.

\section{Do Screens Cause or Reduce Stress?}

\section{To Each Stress, Their Own Screen}

Informed by the fact that stress is a multifaceted adaptive experience [19,21,22,25], our earlier work that motivated this survey postulated that individual differences in stress perception and coping approaches influence the affordances of screen use [1]. In this study, we show that even general factors like age, gender, and self-assessed mental health or situation stress (due to COVID-19) reveal a heterogeneous pattern of preferences and use.

Griffiths and Szabo [14] have long emphasized that, in studying the relation between screens and stress, the context in which a particular media type is adopted is critically important. As Figures 3-6 clearly demonstrate, whether users approach, avoid, or ignore media can vary with age, gender, or mental health status. Our observation (eg, the significant difference in avoid scores between those younger than 25 years and those aged $35-54$ years) on age groups is consistent with previous finding by Kuss et al [37], who have shown a generation-specific ( $Y$ vs X) link between anxiety in developing behavioral dependency on social media use. Interestingly, although we observed a significant difference in preference for games in those younger than 35 years, the differences in game use of those older than 65 years were not significantly different from those who were younger than 25 years or those aged 25-34 years. Even the mean ranks of game use in the older than 65 years category were higher than those aged 55-65 years. This is consistent with findings in a large-scale cross-sectional study by Birks et al [40], who showed that older adults play games for emotion regulation goals (rather than challenge and skill). Although variables such as age and gender are overly reductionist in explaining motivation, uses, and gratifications of different media, we have been able to demonstrate the importance of employing multifactorial, mixed methods inquiries within a media repertoire framework [28,29]. By taking a media repertoire approach within the theoretical framework of studying stress with the appraisal model [23], we have been able to illustrate the complexity of interindividual and intergenerational relationship to different types of media within the particular context of coping with COVID-19 isolation.

\section{The Main Worry About Excessive Screen Time Is Physical Stress}

Although this cross-sectional survey is able to show that some applications of media use may be helpful in psychological destressing, it cannot show whether the same application would become stressful over time. However, examining the concerns of the respondents about potential risk factors can inform whether users appraisal and behavior may change over time.

Applying the appraisal model, we hypothesized that those who have a negative appraisal of the media's affordances for coping would have a different repertoire of media preference and use. Indeed, we found that those who were "Very worried" about both mental health risks and physical health risks also had higher negative appraisal scores - more prone to avoid or ignore media. Interestingly, however, effects of the appraisal of mental health risks and physical health risks on media repertoires were not similar (Figure 6). Compared to those who were "Not worried at all," those who were "Very" or "A little worried" about the physical health risks of screens had increased use of Facebook and Instagram (and a trending, but nonsignificant, higher use of Netflix). In contrast, those who were "Very" or "A little worried" about the mental health risks of screens had increased use of print media and work computers. Recall (Figure 3 ) that age, gender, and self-assessed mental health all played a role in the appraisal of, and preferences for, different media. However, contrary to our expectation, appraisal of mental health risks were not associated with differences in use of social media or Netflix, which were increased in those who were dissatisfied with their mental health (reported it as "Poor" or "Could be Better").

This contradiction is not surprising. Although concerns about mental health stressfulness of media are debatable, either due 
to cultural differences [25], wide misconceptions about the definition of stress [18], or individual reasons for use [6,14-16,36], deleterious physical health effects of excessive screen time are quantifiable $[4,5,41,42]$. One out of four respondents were very worried about the physical health risks of increased screen time, but only 1 out of 7 were concerned about the mental health risks. In about half of the sample, concerns about mental and physical health were concordant. However, the likelihood of responding with "I don't know" was 3 times higher with regard to concern about mental health, compared to physical health.

These observations highlight the complexity of studying the psychological underpinnings of media use, which necessitate integrative mixed methods approaches to studying the harms or benefits of screen-based interventions.

\section{Conclusion}

\section{Summary}

We used a theoretical framework based on Mason's definition of stress (experience of conditions of novelty, unpredictability, threat to self, and sense of control) $[19,20]$ and stipulated that COVID-19 was a stressor. We applied an iterative and multifactorial method to examine the relation between use of media and individual differences in age, gender, and subjective assessments of their stress and mental health state. Using a repertoire-oriented framework, we examined interrelation between different available technologies and the factors that influence individual's choice in the amount of different media or content use.

The data for this survey was collected within the first 4 weeks of North America going into a mandatory lockdown, and its objective was to assess whether (and which) media was serving to destress or was causing more stress. To the best of our knowledge, this is the first study to have employed the media repertoire methodology to investigate the relationship between media use and coping with COVID-19.

Our mixed methods analysis revealed that higher stress was associated with higher prevalence of using passive viewing (streaming service, YouTube, and Instagram), especially in those who did not consider their mental health to be good. The relationship to social media was complex, and although many relied on it for connection, information, and control, many also tried to avoid it for being overwhelming and overhyped. Nevertheless, women were more likely to approach it, and those with mental health complaints were more likely to avoid and ignore it. Our qualitative analyses underlined the importance of positivity and information in helping individuals cope with disruptions in the work or social life, via creating networks of support that connect individuals to resources for training (or retraining), financial planning (or replanning), and social and mental health support.

Our findings are important as they underline the importance of interindividual factors in appraisal and preferences for different media types. Evaluating the affordances and stresses of using screen-based technologies are especially important for those who seek innovative screen-based solutions for helping people to deal with the new realities of this pandemic.

\section{Limitations and Future Work}

We have not used any psychometric instruments to formally assess stress of mental health and have only relied on subjective self-assessments. We have previously shown that self-assessment of stress corresponds to higher scores of stress measured by validated instruments used for measuring stress [1], and omission of such questionnaires helped us shorten the survey and thus have a higher completion rate $(95 \%)$. However, this limits the clinical relevance of our finding and requires follow-up studies.

Although we tried to distribute the survey as widely as possible, as can be seen in Figure 1, more than $90 \%$ of our respondents were in North America, and with a few exceptions, there was no representation from any African countries or important Asian countries like China. In surveys such as this, accessibility to technologies such as streaming services is region dependent. Many countries impose censorship on many types of media, filtering access to services such as social media. Our survey targeted those who could read and write in English. Therefore, the findings and interpretations must not be generalized.

This survey is still open [30], and we hope that by collecting data over time, we will be able to analyze shifts in media use trends as individuals come to like or be bored with certain interventions. In any such future studies, mixed methods multifactorial assessment of the interactions between appraisal and use will remain informative.

\section{Acknowledgments}

This study is supported by PERFORM Centre (Concordia University's Office of Research) support to Media Health Lab.

\section{Conflicts of Interest}

None declared.

\section{Multimedia Appendix 1}

Adaptation of Lazarus' transactional model of stress and coping. The source image on the left is from https://commons.wikimedia.org/wiki/File:Transactional_Model_of_Stress_and_Coping_-_Richard_Lazarus.svg. On the left, a depiction of the adaptation of the model in this study: The novelty, uncontrollability and unpredictability of the COVID-19 pandemic, which is a threat to health and financial resources makes it into a stressor. To cope, individuals who do not have sufficient local resources will use information and communication technologies depending on their needs and preferences, as 
well as their coping styles. The Media usage will be re-appraised in relation to its presumed benefit to mitigate the stress (increase control, reduce threat, and reduce novelty and unpredictability via connection and information.).

[PNG File, 138 KB-Multimedia Appendix 1]

\section{Multimedia Appendix 2}

Responses to Media Appraisal Questionnaire: More than 80\% (548/685) of the respondents indicated that they used social media to be connected while social distancing and remaining connected to what is happening in the world. This was despite the fact that more than $72 \%(506 / 685)$ also thought that social media news where overwhelming them and were spreading false information. For $70 \%$ (480/685) of respondents, social media news and posts about COVID-19 provided a sense of control. About 50\% (345/685) of respondents thought there was too much media hype about COVID-19, and about 29\% (196/685) indicated that they will definitely or somewhat try to avoid the news related to COVID-19. More than 60\% (417/685) of the sample relied on distraction from COVID-19 news, by playing games or watching Television.

[PNG File, $181 \mathrm{~KB}-$ Multimedia Appendix 2]

\section{Multimedia Appendix 3}

Word cloud is generated from the first 1000 words extracted from all responses to all open-answer questions, asking to describe the ways in which the COVID-19 pandemic has disrupted one's life, and what role the individuals envision for media in order to make it beneficial and helpful in coping with the new reality.

[PNG File, 109 KB-Multimedia Appendix 3]

\section{Multimedia Appendix 4}

Examples of responses to open-answer questions.

[DOCX File, 22 KB-Multimedia Appendix 4]

\section{Multimedia Appendix 5}

Relation between mental health and engagement with open-ended questions. Response counts are categorized based on thematic nodes extracted from qualitative analysis. Those who considered themselves in better mental health states seem to have been more elaborate in describing situations or needs related to Work and Positivity. Metal Health 1 = Good; 2, Poor; 3, Could be Better.

[PNG File , 26 KB-Multimedia Appendix 5]

\section{References}

1. Khalili-Mahani N, Smyrnova A, Kakinami L. To Each Stress Its Own Screen: A Cross-Sectional Survey of the Patterns of Stress and Various Screen Uses in Relation to Self-Admitted Screen Addiction. J Med Internet Res 2019 Apr 02;21(4):e11485 [FREE Full text] [doi: 10.2196/11485] [Medline: 30938685]

2. Jung SJ, Winning A, Roberts AL, Nishimi K, Chen Q, Gilsanz P, et al. Posttraumatic stress disorder symptoms and television viewing patterns in the Nurses' Health Study II: a longitudinal analysis. PLoS One 2019;14(3):e0213441 [FREE Full text] [doi: 10.1371/journal.pone.0213441] [Medline: 30897111]

3. Manousaki D, Barnett TA, Mathieu M, Maximova K, Simoneau G, Harnois-Leblanc S, QUALITY Cohort Collaborative Group. Tune out and turn in: the influence of television viewing and sleep on lipid profiles in children. Int J Obes (Lond) 2020 May;44(5):1173-1184. [doi: 10.1038/s41366-020-0527-5] [Medline: 32203106]

4. Golshevsky DM, Magnussen C, Juonala M, Kao K, Harcourt BE, Sabin MA. Time spent watching television impacts on body mass index in youth with obesity, but only in those with shortest sleep duration. J Paediatr Child Health 2020 May;56(5):721-726. [doi: 10.1111/jpc.14711] [Medline: 31821651]

5. Šmotek M, Fárková E, Manková D, Kopřivová J. Evening and night exposure to screens of media devices and its association with subjectively perceived sleep: should "light hygiene" be given more attention? Sleep Health 2020 Mar 17:A. [doi: 10.1016/j.sleh.2019.11.007] [Medline: 32197951]

6. Ryan T, Chester A, Reece J, Xenos S. The uses and abuses of Facebook: a review of Facebook addiction. J Behav Addict 2014 Sep;3(3):133-148. [doi: 10.1556/jba.3.2014.016]

7. von der Heiden JM, Braun B, Müller KW, Egloff B. The association between video gaming and psychological functioning. Front Psychol 2019;10:1731. [doi: 10.3389/fpsyg.2019.01731] [Medline: 31402891]

8. Chóliz M. The challenge of online gambling: the effect of legalization on the increase in online gambling addiction. J Gambl Stud 2016 Jun;32(2):749-756. [doi: 10.1007/s10899-015-9558-6] [Medline: 26058374]

9. Marino C, Gini G, Vieno A, Spada MM. A comprehensive meta-analysis on problematic Facebook use. Comput Hum Behav 2018 Jun;83:262-277. [doi: 10.1016/j.chb.2018.02.009] 
10. Brailovskaia J, Velten J, Margaf J. Relationship between daily stress, depression symptoms, and Facebook addiction disorder in Germany and in the United States. Cyberpsychol Behav Soc Netw 2019 Sep;22(9):610-614. [doi: 10.1089/cyber.2019.0165] [Medline: $\underline{31397593]}$

11. Tsitsika AK, Tzavela EC, Janikian M, Ólafsson K, Iordache A, Schoenmakers TM, et al. Online social networking in adolescence: patterns of use in six European countries and links with psychosocial functioning. J Adolesc Health 2014 Jul;55(1):141-147. [doi: 10.1016/j.jadohealth.2013.11.010] [Medline: 24618179]

12. Lee DS, Orvell A, Briskin J, Shrapnell T, Gelman SA, Ayduk O, et al. When chatting about negative experiences helps-and when it hurts: distinguishing adaptive versus maladaptive social support in computer-mediated communication. Emotion 2020 Apr;20(3):368-375. [doi: 10.1037/emo0000555] [Medline: $\underline{30628816}$ ]

13. Song J, Song TM, Seo D, Jin D, Kim JS. Social big data analysis of information spread and perceived infection risk during the 2015 Middle East respiratory syndrome outbreak in South Korea. Cyberpsychol Behav Soc Netw 2017 Jan;20(1):22-29. [doi: 10.1089/cyber.2016.0126] [Medline: 28051336]

14. Griffiths MD, Szabo A. Is excessive online usage a function of medium or activity? J Behav Addict 2014 Mar;3(1):74-77. [doi: 10.1556/jba.2.2013.016]

15. Pontes HM, Szabo A, Griffiths MD. The impact of Internet-based specific activities on the perceptions of Internet addiction, quality of life, and excessive usage: a cross-sectional study. Addict Behav Rep 2015 Jun;1:19-25 [FREE Full text] [doi: 10.1016/j.abrep.2015.03.002] [Medline: 29531976]

16. Utz S, Breuer J. The relationship between use of social network sites, online social support, and well-being: results from a six-wave longitudinal study. J Media Psychol 2017;29(3):115-125 [FREE Full text] [doi: 10.1027/1864-1105/a000222] [Medline: 29147141]

17. Pretorius C, Chambers D, Cowan B, Coyle D. Young people seeking help online for mental health: cross-sectional survey study. JMIR Ment Health 2019 Aug 26;6(8):e13524 [FREE Full text] [doi: 10.2196/13524] [Medline: 31452519]

18. Souza-Talarico JN, Wan N, Santos S, Fialho PPA, Chaves EC, Caramelli P, et al. Cross-country discrepancies on public understanding of stress concepts: evidence for stress-management psychoeducational programs. BMC Psychiatry 2016 Jun 03;16:181 [FREE Full text] [doi: 10.1186/s12888-016-0886-6] [Medline: 27260184]

19. MASON JW. A review of psychoendocrine research on the pituitary-adrenal cortical system. Psychosom Med 1968;30(5):576-607. [doi: 10.1097/00006842-196809000-00020]

20. Lupien S, Ouellet-Morin I, Trépanier L, Juster R, Marin M, Francois N, et al. The DeStress for Success Program: effects of a stress education program on cortisol levels and depressive symptomatology in adolescents making the transition to high school. Neuroscience 2013 Sep 26;249:74-87. [doi: 10.1016/j.neuroscience.2013.01.057] [Medline: 23403176]

21. Folkman S, Moskowitz JT. Coping: pitfalls and promise. Annu Rev Psychol 2004;55:745-774. [doi: 10.1146/annurev.psych.55.090902.141456] [Medline: 14744233 ]

22. McEwen BS, Akil H. Revisiting the stress concept: implications for affective disorders. J Neurosci 2020 Jan 02;40(1):12-21. [doi: 10.1523/jneurosci.0733-19.2019]

23. Lazarus RS, Folkman S. Stress, Appraisal, and Coping. New York: Springer; 1984:1-445.

24. Nasca C, Menard C, Hodes G, Bigio B, Pena C, Lorsch Z, et al. Multidimensional predictors of susceptibility and resilience to social defeat stress. Biol Psychiatry 2019 Sep 15;86(6):483-491. [doi: 10.1016/j.biopsych.2019.06.030] [Medline: $\underline{31466563]}$

25. Tweed RG, White K, Lehman DR. Culture, stress, and coping. J Cross-Cultural Psychol 2016 Jul 26;35(6):652-668. [doi: 10.1177/0022022104270109]

26. Qiu J, Shen B, Zhao M, Wang Z, Xie B, Xu Y. A nationwide survey of psychological distress among Chinese people in the COVID-19 epidemic: implications and policy recommendations. Gen Psych 2020 Mar 06;33(2):e100213. [doi: 10.1136/gpsych-2020-100213]

27. Khalili-Mahani N, Assadi A, Li K, Mirgholami M, Rivard M, Benali H, et al. Reflective and reflexive stress responses of older adults to three gaming experiences in relation to their cognitive abilities: mixed methods crossover study. JMIR Ment Health 2020 Mar 26;7(3):e12388 [FREE Full text] [doi: 10.2196/12388] [Medline: 32213474]

28. Hasebrink U, Popp J. Media repertoires as a result of selective media use. A conceptual approach to the analysis of patterns of exposure. Communications 2006;31(3):369-387. [doi: 10.1515/commun.2006.023]

29. Hasebrink U, Hepp A. How to research cross-media practices? Investigating media repertoires and media ensembles. Convergence 2017 Apr 07;23(4):362-377. [doi: 10.1177/1354856517700384]

30. SurveyMonkey. URL: https://www.surveymonkey.com/r/MediaCovid19

31. Bastian M, Heymann S, Jacomy M. Gephi: an open source software for exploring and manipulating networks. 2009 Presented at: 3rd International AAAI Conference on Weblogs and Social Media; 2009; St Jose, USA. [doi: 10.13140/2.1.1341.1520]

32. Khalili-Mahani N, De Schutter B. Affective game planning for health applications: quantitative extension of gerontoludic design based on the appraisal theory of stress and coping. JMIR Serious Games 2019 Jun 06;7(2):e13303 [FREE Full text] [doi: 10.2196/13303] [Medline: 31172966]

33. Bowey JT, Friehs MA, Mandryk RL. Red pill or blue pill. 2019 Presented at: 14th International Conference on the Foundations of Digital Games; 2019; San Luis Obispo, CA, USA p. 1-11. [doi: 10.1145/3337722.3337734] 
34. Khalili-Mahani N, De Schutter B, Mirgholami M, Holowka EM, Goodine R, DeJong S, et al. For whom the games toll: a qualitative and intergenerational evaluation of what is serious in games for older adults. Comput Game J 2020 Mar 11;9(2):221-244. [doi: 10.1007/s40869-020-00103-7]

35. Ryan RM, Rigby CS, Przybylski A. The motivational pull of video games: a self-determination theory approach. Motiv Emot 2006 Nov 29;30(4):344-360. [doi: 10.1007/s11031-006-9051-8]

36. Castro D, Rigby JM, Cabral D, Nisi V. The binge-watcher's journey: investigating motivations, contexts, and affective states surrounding Netflix viewing. Convergence 2019 Dec 04:135485651989085. [doi: 10.1177/1354856519890856]

37. Kuss DJ, Kanjo E, Crook-Rumsey M, Kibowski F, Wang GY, Sumich A. Problematic mobile phone use and addiction across generations: the roles of psychopathological symptoms and smartphone use. J Technol Behav Sci 2018;3(3):141-149 [FREE Full text] [doi: 10.1007/s41347-017-0041-3] [Medline: 30238057]

38. de Hoog N, Verboon P. Is the news making us unhappy? The influence of daily news exposure on emotional states. Br J Psychol 2020 May;111(2):157-173 [FREE Full text] [doi: 10.1111/bjop.12389] [Medline: 30900253]

39. Marin M, Morin-Major J, Schramek TE, Beaupré A, Perna A, Juster R, et al. There is no news like bad news: women are more remembering and stress reactive after reading real negative news than men. PLoS One 2012;7(10):e47189 [FREE Full text] [doi: 10.1371/journal.pone.0047189] [Medline: 23071755]

40. Birk MV, Friehs MA, Madnryk RL. Age-based preferences and player experience. 2017 Presented at: The Annual Symposium on Computer-Human Interaction in Play; 2017; Amsterdam p. 157-170. [doi: 10.1145/3116595.3116608]

41. Saunders TJ, Vallance JK. Screen time and health indicators among children and youth: current evidence, limitations and future directions. Appl Health Econ Health Policy 2017 Jun;15(3):323-331. [doi: 10.1007/s40258-016-0289-3] [Medline: 27798796]

42. Saunders TJ, Chaput J, Tremblay MS. Sedentary behaviour as an emerging risk factor for cardiometabolic diseases in children and youth. Can J Diabetes 2014 Feb;38(1):53-61. [doi: 10.1016/j.jcjd.2013.08.266] [Medline: 24485214]

\section{Abbreviations \\ COVID-19: coronavirus disease \\ EC: eigenvector centrality \\ MERS: Middle East respiratory syndrome}

Edited by G Eysenbach; submitted 15.05.20; peer-reviewed by K Aguirre, M Friehs, C Escalona-Marfil; comments to author 13.07.20;
revised version received 21.07.20; accepted 22.07.20; published 06.08.20
Please cite as:
Pahayahay A, Khalili-Mahani N
What Media Helps, What Media Hurts: A Mixed Methods Survey Study of Coping with COVID-19 Using the Media Repertoire
Framework and the Appraisal Theory of Stress
J Med Internet Res 2020;22(8):e20186
URL: $\underline{\text { htps://www.jmir.org/2020/8/e20186 }}$
doi: $\underline{10.2196 / 20186}$
PMID: $\underline{32701459}$

(C)Amber Pahayahay, Najmeh Khalili-Mahani. Originally published in the Journal of Medical Internet Research (http://www.jmir.org), 06.08.2020. This is an open-access article distributed under the terms of the Creative Commons Attribution License (https://creativecommons.org/licenses/by/4.0/), which permits unrestricted use, distribution, and reproduction in any medium, provided the original work, first published in the Journal of Medical Internet Research, is properly cited. The complete bibliographic information, a link to the original publication on http://www.jmir.org/, as well as this copyright and license information must be included. 